\title{
The role of alkali metal and alkaline metal earth in natural zeolite on combustion of Albizia Falcataria sawdust
}

\author{
Mokh. Hairul Bahri ${ }^{1}$. Widya Wijayanti ${ }^{2}$. Nurkholis Hamidi' ${ }^{2}$ I. N. G. Wardana ${ }^{2}$
}

Received: 14 July 2019 / Accepted: 23 September 2019 / Published online: 11 January 2020

(c) The Author(s) 2020

\begin{abstract}
The combustion process of Albizia falcataria (AF) sawdust with the addition of natural zeolite (NZ) was observed experimentally using PT 1600 LINSEIS Simultaneous thermal analyzer (STA). The results showed that alkali metal and alkaline metal earth in NZ play an essential role in the process of decomposing the Hemicellulose AF molecule. The results of the molecular analysis show that the chemical balance of the mixture determines the combustion temperature. Excess NZ becomes a thermal burden which slows down the combustion reaction because heat does not sufficiently activate alkali metal and alkaline metal earth in NZ. In a small amount, NZ is less involved in the AF decomposition process. It shows that a mixture of $\mathrm{AF}$ and $\mathrm{NZ}$ can increase combustion kinetic in the right mix. Addition of $15-20 \%$ of NZ decreases the ignition temperature within faster burning rate. Activated alkali metal and alkaline metal earth decompose hemicellulose faster so that they burn completely in minimizing pollutant and maximizing LHV. Greater NZ completes the decomposition much earlier so that at the resting time of the process NZ slightly absorbs heat sinking LHV. The drastic reduction of Ca due to $\mathrm{NZ}$ make the fuel is suitable for boiler because $\mathrm{Ca}$ is responsible for agglomeration and corrosion.
\end{abstract}

Keywords Albizia falcataria $\cdot$ Ignition temperature $\cdot$ Combustion kinetic $\cdot$ Zeolite catalyst

\section{Introduction}

Albizia falcataria (AF) is one of the most widely planted trees in Indonesia because it is quickly harvested at the age of 5-7 years $[1,2]$. AF is processed into semi-finished material and then made into pallets, wooden crates. AF sawmills produce large amounts of sawdust waste. The waste of wood sawdust from AF processing in Indonesia will continue to grow because of the short harvest age of the plant and thus become an environmental problem. The research on application of sawdust biomass fuel and the effort to improve boiler efficiency have been done in the last decade [3-5]. The effect

Mokh. Hairul Bahri

mhairulbahri@unmuhjember.ac.id

$\bowtie$ I. N. G. Wardana

wardana@ub.ac.id

1 Department of Mechanical Engineering, Universitas Muhammadiyah Jember, J1. Karimata 49, Jember, East Java 68152, Indonesia

2 Department of Mechanical Engineering, Brawijaya University, Jl. MT. Haryono 167, Malang, East Java 65145, Indonesia of the biomass fuel on the boiler corrosion has also been studied [6]. To get better understanding on the combustion characteristics of sawdust, this paper provides a scientific discussion about the use NZ to improve sawdust as fuel.

Biomass combustion reaction occurs in many steps [7], namely: heating, pyrolysis (volatiles), pre-combustion reaction, primary gas-phase combustion, secondary combustion, effluent stack gas. Some previous researchers conducted pyrolysis of biomass with additional zeolites capable of producing more gas. The researcher [8] used H-ZSM-5 for pyrolysis of pine and cypress whose results explained that the function of catalyst acid was able to increase aromatic concentration. Whereas $[9,10]$ made pyrolysis of the various types of wood chips by adding ZSM5 discontinuously and additional stainless steel ball bearings to make pyrolysis effective. Stainless steel ball bearings inhibit pyrolysis vapor and expand the hot surface during thermal cracking. The result shows that the percentage of $\mathrm{H}, \mathrm{CH}_{4}, \mathrm{C}_{2} \mathrm{H}_{4}$, $\mathrm{C}_{3} \mathrm{H}_{6}$ gas increases with the addition of zeolite. The study was conducted [11] on the pyrolysis of beech wood (Fagus sylvatica L.) with five types of zeolites (SN-27, MSN-15, MSM-15, H-ZSM-5-28, and H-ZSM-5-80) to determine its effect on lignocellulose. The results showed that zeolite acid 
catalyst increases the amount of Fulfural and Levoglucosan. H-ZSM-5 with lower alumina content is the most effective in improving furfural because of better molecular diffusion through pores. Overall, the above research shows that acid catalyst can improve the final yield of lignocelluloses thermal degradation in pyrolysis. This suggests that additional zeolite must also improve reaction that makes combustion characteristics better. Therefore, the present study aims to uncover the role of natural zeolite (NZ) on combustion process of AF.

Analysis of biomass combustion using thermogravimetry is important to know the thermochemical conversion of combustible solid waste. The burning process of mixture of pine sawdust and coal was analyzed using a thermogravimetric analyzer [12]. The result shows that pine sawdust is decomposed at the beginning then followed by coal and pine charcoal which are burned together at the same time. The study [13] mixed cellulose, xylan and lignin with coal and then analyzed its burning process using a thermogravimetric analyzer. The result is that lignocellulose can increase the rate of devolatization, reduce flame temperature, and accelerate charcoal combustion. The thermogravimetric analysis of additional catalysts $\left(\mathrm{KOH}, \mathrm{NaOH}, \mathrm{KCl}, \mathrm{CuCl}_{2} / \mathrm{KCl}\right.$, and $\mathrm{CaCl}_{2} / \mathrm{CaO}$ ) in burning of Municipal Solid Waste found the flame temperature reduced. At a temperature of $200{ }^{\circ} \mathrm{C}$ Municipal Solid Waste with the addition of $\mathrm{KOH}$ catalyst, $\mathrm{CuCl}_{2} / \mathrm{KCl}$, and $\mathrm{CaCl}_{2} / \mathrm{CaO}$ have been degraded $5 \%$ while others are still below it [14]. Research on thermogravimetric analysis by burning rice and wheat straw with additional catalysts ( $\mathrm{NiO}, \mathrm{CuO}, \mathrm{CaO}$, and $\mathrm{MgO}$ ) was carried out [15]. The result is that the $\mathrm{MgO}$ catalyst at $200{ }^{\circ} \mathrm{C}$ has burned more than $5 \%$ of rice straw while the others are lower. It means that the catalyst can increase the rate of the volatility of biomass. The same study was done by [16] investigating using a thermogravimetric analyzer. In this study, combustion of peanut shells, rice husks and wheat straw added with organic calcium compounds were analyzed. The result shows that the index of peanut skin and wheat straw burning performance increase while the rice husk decreases. It is due to the lowest $\mathrm{C}$ and $\mathrm{H}$ content of rice husks compared to the others so the percentage of catalysts must be different.

Scientific data about the use of natural catalysts is very limited, so more researches are needed. This study describes the combustion of sawdust AF with the addition of Natural Zeolite (NZ) using a thermogravimetric analyzer as a reactor. A good understanding of the decomposition of biomass during the thermochemical conversion process is very important for the efficiency of the process and its technology utilization [17].

Many NZ are available in Indonesia, making them easy to obtain and cheap. NZ mines are found in the southern part of Java, starting from Malang, Pacitan-East Java and Cikembar, Cipatujah, Bayah—West Java. So far NZ has been applied only for dehydration of ethanol and transesterification of crude palm oil $[18,19]$. The study of improving biomass combustion using NZ is rarely found. Therefore this study provides a discussion of $\mathrm{NZ}$ applied to improve biomass combustion characteristics. Since NZ contains a lot of minerals which easily disintegrate and become active when they get enough thermal energy, then the discussion emphasizes the role of minerals in NZ for molecular decomposition of hemicellulose.

\section{Materials and Methods}

\subsection{Materials and properties analysis}

The AF used in this study was taken from sawmills in Lumajang, East Java, Indonesia. AF was dried in the sun and crushed to a size of 100 mesh. The ultimate analysis and proximate analysis were carried out using LECO CHN -2000 and S-632 equipment. The AF composition was analyzed to determine the percentage of cellulose, hemicellulose, and lignin content as shown in Table 1a. It is seen that AF consists mostly of volatile matter but also contains very little sulfur and nitrogen as well. Three main elements are forming AF, detected carbon which is almost the same as oxygen and hydrogen; there is a small part. The structure of

Table 1 a Characterization of Albizia Falcataria. b. XRD analysis of NZ

\begin{tabular}{ll}
\hline (a) & \\
Ultimate analysis (dry basis, wt.\%) & 45.53 \\
Carbon & 6.49 \\
Hydrogen & 0.31 \\
Nitrogen & 0.1 \\
Sulfur & 46.13 \\
Oxygen & \\
Proxymate analysis (dry basis, wt $\%)$ & 7.2 \\
Moisture & 74.9 \\
Volatile matter & 16.46 \\
Fixed Carbon & 1.44 \\
Ash & 18.229 \\
Gross Caloric Value (J/g) & \\
Compotional analysis (\%) & 41.88 \\
Cellulose & 14.55 \\
Hemicellulose & 24.78 \\
Lignin & \\
(b) & $\mathrm{Al}_{8.16} \mathrm{Si}_{27.84} \mathrm{O}_{97.52}$ \\
Chemical formula & $\mathrm{Na}_{4.00} \mathrm{Ca}_{1.88} \mathrm{~K}_{0.28}$ \\
& $\mathrm{Mg}_{0.08}$ \\
Crystal system & 2.17 \\
Density (g/cm ${ }^{3}$ ) & \\
\hline
\end{tabular}


the composition of the AF-forming compound such as lignocellulose generally consists of cellulose at most followed by lignin and hemicellulose.

NZ was obtained from mining in Malang, East Java, Indonesia, cleaned with distilled water and it was crushed into the same size as AF sawdust. NZ is characterized using XRD to determine the mineral content and crystal structure. The XRD analysis results are listed in Table 1b. NZ chemical formula is dominated by Oxygen and $\mathrm{Si}$ and $\mathrm{Al}$ which are the main elements that form the tetrahedral structure. Also detected are alkali metal and alkaline metal earth elements as ions counterbalancing $\mathrm{Al}-\mathrm{O}$ bonds to create a tetrahedral structure.

\section{Thermogravimetric analysis}

Sawdust combustion from AF with a mixture of NZ was analyzed using PT 1600 LINSEIS Simultaneous thermal analyzer (STA) as a reactor shown in Fig. 1. This technique was also applied in $[20,21]$. The sample is placed in the sample pan while the reference pan is usually empty, tested at three different initial weight AF; AF $1=10 \mathrm{mg}$, $\mathrm{AF} 2=15 \mathrm{mg}$ and AF3 $=20 \mathrm{mg}$. The addition of NZ to the test sample are $15 \%$ and $25 \%$ of the initial weight AF, namely, AF1 + NZ (15\% xAF1) and so on. Samples at three different weights were burned from room temperature to $900{ }^{\circ} \mathrm{C}$ with a heating rate of $80^{\circ} \mathrm{C} / \mathrm{min}$ and air flow of $5 \mathrm{Ls} /$ min [22], then held for $10 \mathrm{~min}$ at $900{ }^{\circ} \mathrm{C}$ for a complete combustion. Heating using a heating element (heater) was controlled by the CPU. Airflow is generated using a compressor that is regulated using valves and flow indicator meters. Temperature is measured using a thermocouple attached to the sample pan and reference. Weight changes are weighed by the scale connected with the sample pan and reference. These weight changes are then recorded as relative weight loss $(\mathrm{TG})=\frac{m}{m_{0}}(\%)$, where $\mathrm{m}$ is instantaneous mass of the sample and $m_{0}$ is initial mass of the sample. The rate of relative weight loss was estimate from time derivative of TG as $=\frac{d(T G)}{d t}$.

\subsection{Catalytic Combustion Analysis}

The use of NZ catalysts on combustion sawdust AF can reduce the ignition temperature so that it can achieve lower activation energy. The formula of the Conversion Degree of Combustible (CDC) is used to calculate the temperature around wood powder $[23,24]$ based on data from TG defined as in Eq. 1.

$\frac{\mathrm{CDC}}{100}=\frac{m_{o}-m}{m_{o}-m_{\infty}}$ or $\mathrm{CDC}=\frac{m_{o}-m}{m_{o}-m_{\infty}} \times 100[\%]$,

where $m_{\infty}$ is the final mass of the sample obtained from STA. Besides the temperature around sawdust AF powder, CDC is also used to estimate the effect of NZ on combustion of AF. There are two parameters used to estimate the effect of $\mathrm{NZ}$ on AF. One is the temperature when CDC of the sample reaches 5\% and the other one is the $\mathrm{CDC}$ when temperature reaches $900{ }^{\circ} \mathrm{C}$ [14].

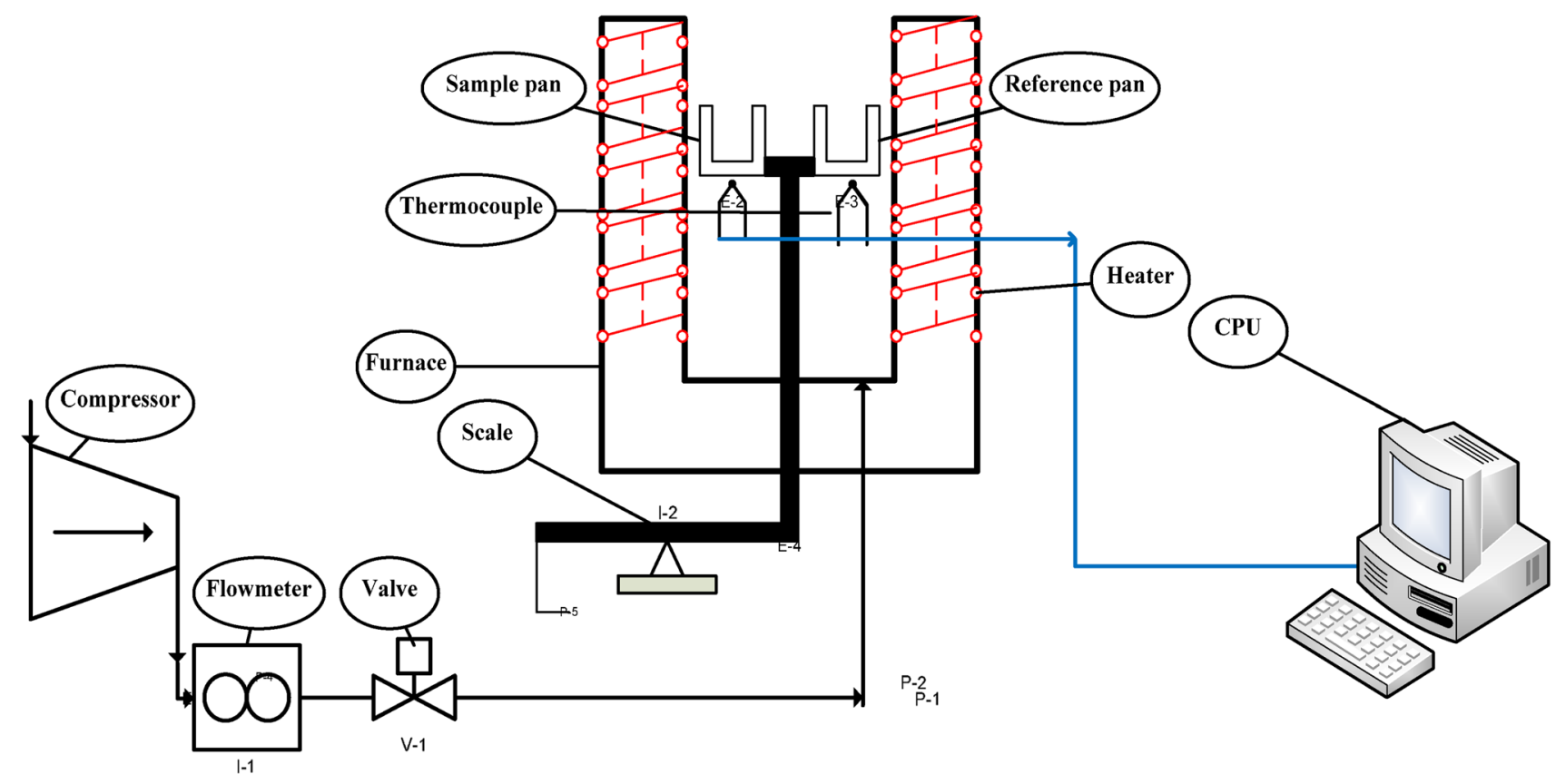

Fig. 1 Schematic principle of STA 


\section{Chemical analysis of ash}

The ash from AF combustion was analyzed using SEM (FEI INSPECT tipe S50). This instrument was also equipped with EDAX which is useful to analyze the content of the ash surface structure. The content of the ash is presented in Table 2.

\section{Result and discussion}

\section{TG and DTG analysis}

Biomass combustion occurs in two main stages: de-volatilization stage and oxidation stage [21]. Likewise, burning a mixture of AF and NZ also can be divided into two phases. The first is volatile combustion, and the second is fixed char combustion.

Data obtained from the reactor are time, temperature, relative weight loss $(\mathrm{m} / \mathrm{mo})$ and derivatives of relative weight loss. In burning AF, the catalyst works more effectively in combustion when lowering the flame temperature. The effect of adding catalysts at combustion AF is high when a sudden increase in CDC occurs at a lower ignition temperature. In this paper, the impact of adding NZ percentages and initial weight differences are discussed.

Figure 2 describes TG (Relative weight loss, right side) and DTG (Derivative weight loss, left side) at combustion AF, $\mathrm{AF}+15 \% \mathrm{NZ}$, and $\mathrm{AF}+25 \% \mathrm{NZ}$ at various $\mathrm{AF}$ weights. The lignocellulose content in AF in Table 1a refers to [25] according to the general biomass content. Solid line represents TG and dashed line represents DTG.

Figure 2a explains about TG-DTG at the initial weight of $10 \mathrm{mg}$. Combustion AF1 without NZ have faster weight degradation. It is because NZ is a thermal burden as the heat from combustion is small so it cannot activate minerals in NZ. Consequently, ash containing $\mathrm{SiO}_{2}$ and $\mathrm{Al}_{2} \mathrm{O}_{3}$ is burned so that there is still residue in the pan [26]. Adding NZ to AF causes the percentage of ash to increase because $\mathrm{Si}$ and $\mathrm{Al}$ elements arrange the compounds. At the end of the process, the percentage of TG of combustion ash AF2 with the addition of NZ is higher than that without additives.

In Fig. $2 \mathrm{~b}$ for sample weight of $15 \mathrm{mg}$, the rate of weight reduction in combustion $\mathrm{AF} 2+15 \% \mathrm{NZ}$ is slower than $\mathrm{AF} 2+25 \% \mathrm{NZ}$. That is because hemicellulose, cellulose, and lignin decompose together due to the NZ catalysis effect. It is seen that the blue line (TG) is steeper than the red line (TG), but when the temperature approaches $600{ }^{\circ} \mathrm{C}$, the blue line (DTG) rises almost to zero indicating that hemicellulose, cellulose, and lignin burnout. At the end of the combustion, only NZ is left so that the ash percentage is $25 \%$ more at $\mathrm{AF} 2+25 \% \mathrm{NZ}$; the blue line (TG) is more than the red line (TG). The residue of using NZ is almost half of that at $10 \mathrm{mg}$ sample (Fig. 2a) indicating that NZ work better.

In Fig. 2c NZ has started working and controlling combustion. At $20 \mathrm{mg}$ AF combustion, NZ has enough heat to be active even though $\mathrm{AF}+25 \% \mathrm{NZ}$ has not been burned better than $\mathrm{AF}+15 \% \mathrm{NZ}$. It can be seen that in burning lignin (fixed carbon) at temperatures above $600{ }^{\circ} \mathrm{C}$, the DTG blue line is close to zero followed by red and black lines. It means that at the fix carbon combustion stage, NZ could break down lignin faster than without NZ. The percentage of ash which is around $20 \%$ equals to the percentage of NZ in the AF. This shows that the AF burned completely indicating that the burning of AF with NZ is almost free of pollutant emission. This result is supported by Table 2 which presents that the ash mainly contains $\mathrm{Si}$ and $\mathrm{O}$ and then $\mathrm{Al}$, these are the main elements in NZ while C was completely disappear.

\section{Influence of NZ on catalytic combustion}

Figure 3 shows the CDC which explains the influence of NZ on combustion AF. CDC index compares the character of combustion by measuring temperature when the weight loss reaches 5\% [14]. The higher the CDC temperature means the effect of the catalyst does not affect the combustion of $\mathrm{AF}$. Whereas on the contrary, it is true that the catalyst has a significant effect on combustion AF. For an initial weight of $10 \mathrm{mg}$ (Fig. 3) the addition of NZ does not increase the rate of weight degradation. AF without NZ is at a lower ignition temperature, followed by additions of $15 \%$ and $25 \% \mathrm{NZ}$ at higher temperatures. $\mathrm{CDC} \mathrm{AF}$ temperature occurs at a temperature of $253{ }^{\circ} \mathrm{C}$, while an additional $15 \% \mathrm{NZ}$ makes the CDC AF occur at a temperature of $275^{\circ} \mathrm{C}$.

Furthermore, the addition of $\mathrm{NZ}$ to $25 \%$ makes CDC AF occur at $309{ }^{\circ} \mathrm{C}$. That happened because the weight of AF burned too little and the heat produced by combustion was absorbed by NZ so that it was not enough to make minerals in NZ become active to help combustion in other words NZ only became a thermal burden. As a result, $\mathrm{AF}+\mathrm{NZ}$ requires higher amount of heat to burn.

In Fig. 4 with the addition of NZ to the initial weight of $15 \mathrm{mg}$ in combustion, AF shows the difference in temperature of the CDC. The addition of $15 \%$ of NZ causes CDC AF
Table 2 Chemical analysis results of ash

\begin{tabular}{llllllllllll}
\hline Element & $\mathrm{C}$ & $\mathrm{O}$ & $\mathrm{Na}$ & $\mathrm{Mg}$ & $\mathrm{Al}$ & $\mathrm{Si}$ & $\mathrm{P}$ & $\mathrm{S}$ & $\mathrm{K}$ & $\mathrm{Ca}$ & $\mathrm{Fe}$ \\
\hline $\mathrm{AF}$ & 10.5 & 35.2 & 2.8 & 2.0 & 1.8 & 14.5 & 1.3 & 0.3 & 2.9 & 24.5 & 3.8 \\
$\mathrm{AF}+15 \% \mathrm{NZ}$ & 16.5 & 39.3 & 0.4 & 0.2 & 4.3 & 29.4 & - & - & 3.9 & 4.6 & 1.0 \\
$\mathrm{AF}+25 \% \mathrm{NZ}$ & - & 45.2 & 1.5 & 0.8 & 7.2 & 37.0 & - & - & 4.3 & 1.8 & 1.8 \\
\hline
\end{tabular}



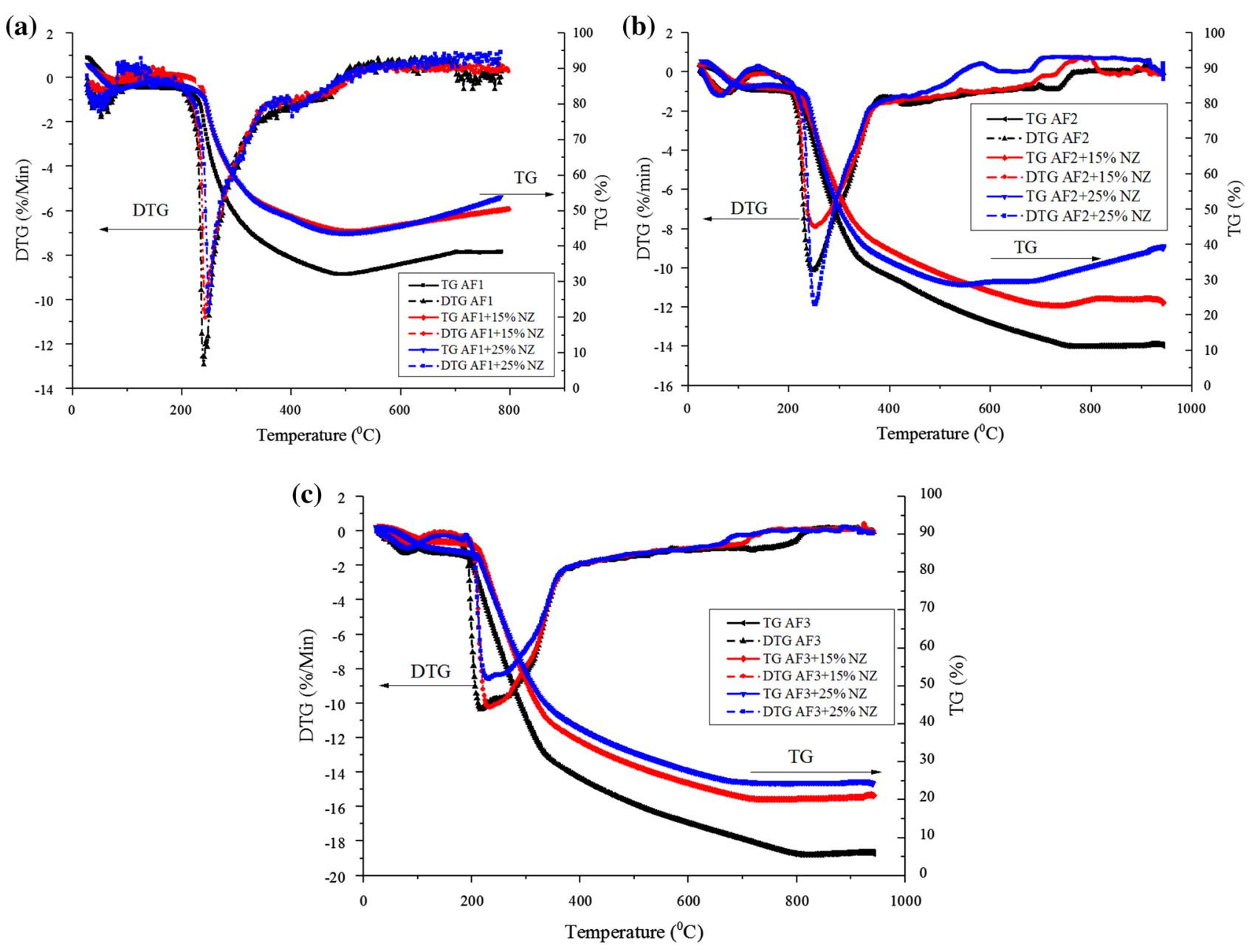

Fig. 2 DTG $-\mathrm{TG}$ AF vs. Temperature. a AF1 = $10 \mathrm{mg} ; \mathbf{b}$ AF2 $=15 \mathrm{mg}$; $\mathbf{A F} 3=20 \mathrm{mg}$

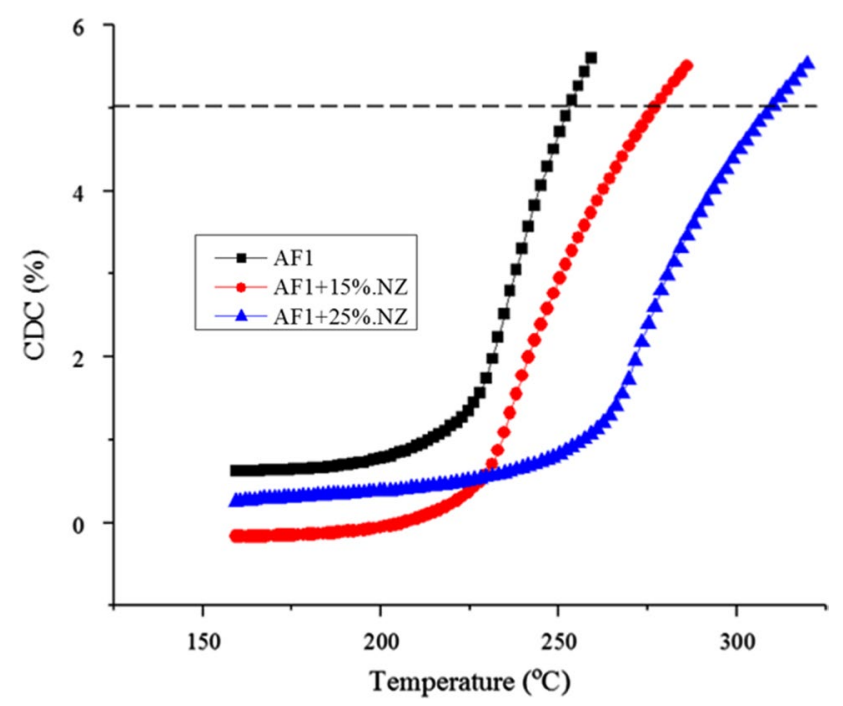

Fig. 3 CDC AF $10 \mathrm{mg}$ vs. Temperature

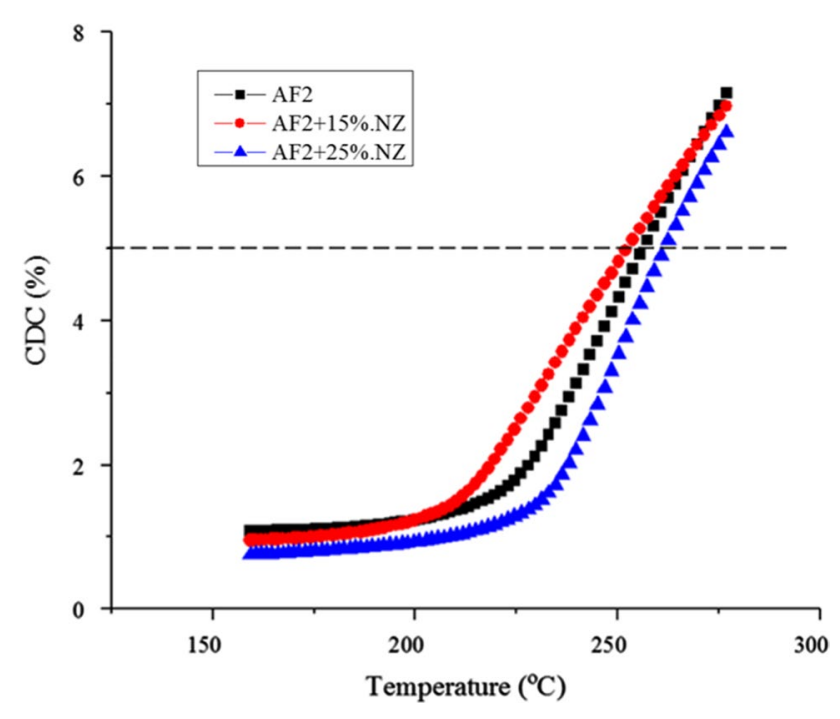

Fig. 4 CDC AF $15 \mathrm{mg}$ vs. Temperature 
at the lowest temperature $\left(251,256\right.$, and $\left.259^{\circ} \mathrm{C}\right)$. The same thing happens at the initial weight of $20 \mathrm{mg}$, which is shown in Fig. 5. Addition of $15 \%$ of NZ gives the lowest CDC temperature. It shows that the amount of heat is only enough to activate $\mathrm{NZ}$ to $15 \%$. Above that percentage, NZ became a thermal load.

$\mathrm{AF}+\mathrm{NZ}$ sawdust combustion with an initial weight of $20 \mathrm{mg}$ has the lowest CDC temperature (234, 239, and $248^{\circ} \mathrm{C}$ ) (Fig. 5). That is, the heat from the fuel has been able to activate $\mathrm{NZ}$ to $25 \%$ even though in this amount $\mathrm{NZ}$ is not as active as $15 \%$.

In Figs. 4 and 5 there is a red line which is $\mathrm{AF}+15 \%$ NZ increasing precedently at $214{ }^{\circ} \mathrm{C}$ and $208{ }^{\circ} \mathrm{C}$. It is due to the composition of the right mixture in $\mathrm{AF}+\mathrm{NZ}$ so that $\mathrm{NZ}$ can break AF bonds thoroughly. AF sawdust $14.55 \%$ of its content is hemicellulose which will be decomposed

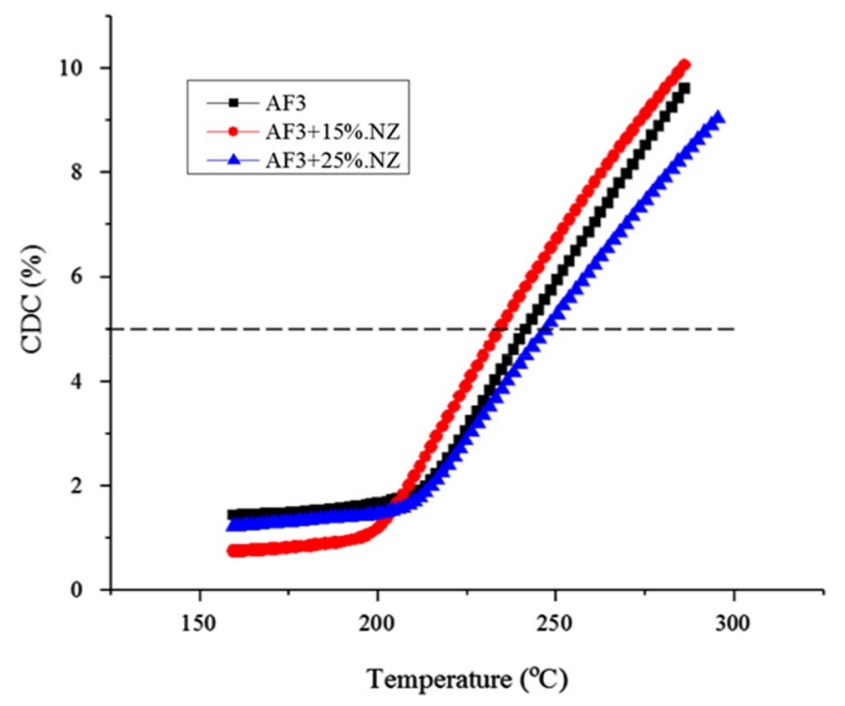

Fig. 5 CDC AF $20 \mathrm{mg}$ vs. Temperature by heat energy together with the change in NZ structure. Hemicellulose consists of several polymers, e.g., xylan. The Explanation of polymer breakdown in this discussion use xylan for the main polymer that forms hemicellulose [27, 28]. Hemicellulose consists of branched polymers which are more easily broken down than cellulose. One of the essential branches is xylan, so if there is an initial decomposition of combustion, it can be predicted that it is xylan [29,30]. Data obtained after processing proves that the addition of $\mathrm{NZ}$ can reduce the decomposition temperature of lignocellulose AF as the results of research conducted by [31].

During the combustion process, some heat energy makes $\mathrm{NZ}$ release $\mathrm{Na}^{+}, \mathrm{Mg}^{2+}, \mathrm{K}^{+}$, and $\mathrm{Ca}^{2+}$ (Alkali metal and Alkaline metal earth) as counterbalancing ions (Fig. 6). Alkali metal and alkaline metals earth are more energetic atoms in tearing the connecting oxygen between the monomers of hemicellulose in AF so that the hemicellulose will be broken into shorter bonds (Fig. 7).

It can be seen in the NZ structure in Fig. 6 that alkali metal and alkaline metal earth in $\mathrm{NZ}$, namely $\mathrm{Na}, \mathrm{Mg}, \mathrm{K}$, and $\mathrm{Ca}$ act as counterbalancing of $\mathrm{Al}-\mathrm{O}$ and $\mathrm{Si}-\mathrm{O}$ to form tetrahedral structures in NZ. When NZ is heated the structure changes to Bronsted acid by releasing $\mathrm{Na}^{+}, \mathrm{Mg}^{2+}, \mathrm{K}^{+}$, and $\mathrm{Ca}^{2+}$. These ions will make the partial negative oxygen connecting the hemicellulose polymer bonds experience a continuous attracting force which eventually dislodges. As a result, the polymer will turn into a monomer (Fig. 6). It results in $15 \mathrm{mg}$ of AF burning faster at lower temperatures because of shorter bonds which are more flammable. The results of this study are in accordance with the study in [32, 33] which explained that alkali metal and alkaline metal earth are useful catalysts for pyrolysis, combustion, and gasification.

Larger alkali metal and alkaline metal earth molecules disrupt oxygen which binds polymer carbon so that the
Fig. 6 The proposed mechanism for catalytic combustion of AF (Hemicellulose) and NZ blends

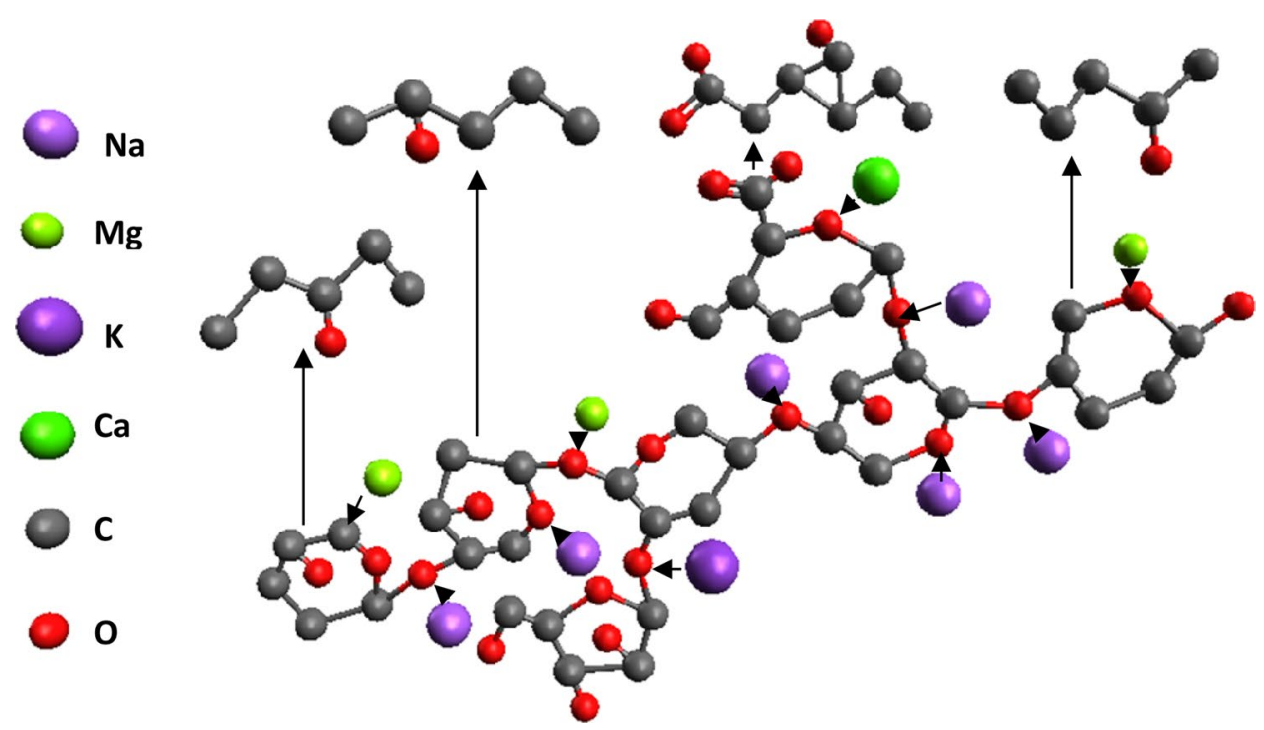


Fig. 7 Termination of polymer bonds by $\mathrm{Na}^{+}$, a L-Arabinose, $\mathbf{b}$ Valeric acid, $\mathbf{c}$ Levulinic acid, $\mathbf{d}$ Ethylene glycol

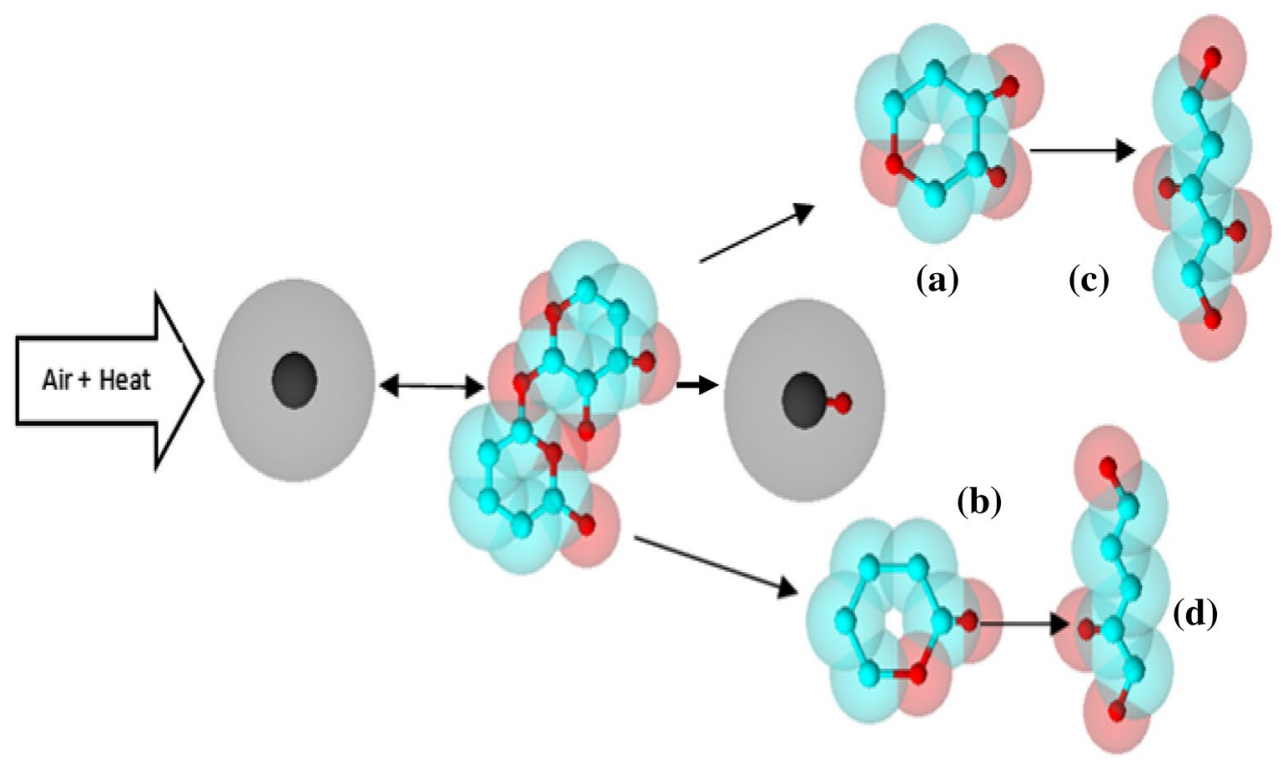

polymeric bonds will be broken. For small initial fuel mass (10 mg), the addition of NZ causes AF to burn more slowly at higher temperatures because the heat energy from combustion of AF is not enough to activate zeolite to release alkali metal and alkaline metal earth ions so that it only functions as a thermal load. It is different for the initial weight of 15 and $20 \mathrm{mg}$, especially in $15 \% \mathrm{NZ}$ which can break the hemicellulose chain faster. This mechanism is caused by the volatility of AF before it burns. At the same time, alkali metal and alkaline metal earth in NZ have got enough heat energy to be activated and released so that they attract oxygen polymer chains (red lines in Figs. 4 and 5). For the addition of $25 \% \mathrm{NZ}$ there is a slowdown in flame temperature because heat is absorbed more by NZ than AF so that the process of AF volatility it is slower (blue lines in Figs. 4 and 5).

Figure 7 illustrates that air flow and heat make alkali metal and alkaline metal earth, e.g., black $\mathrm{Na}$ which is released from the NZ. Na attracts red oxygen from the polymer bonds so that the broken bonds are shorter a and $\mathrm{b}$. $\mathrm{Na}-\mathrm{O}$ bonds is temporary, making $\mathrm{Na}$ (or other balancing ions) separated into free atoms to break other bonds (a) and (b) with the same mechanism so that they become short chain bonds that are more flammable.

$\mathrm{Na}$ electron in the outer shell induces $\mathrm{O}$ electrons because the $\mathrm{C}-\mathrm{O}-\mathrm{C}$ bond is weakened due to heat. As a result, the $\mathrm{C}-\mathrm{O}-\mathrm{C}$ bond is broken so that the polymer turns into a monomer. The electron of $\mathrm{Na}$ (or another balancing ion) induces and attracts $\mathrm{O}$ atoms that weaken $\mathrm{O}-\mathrm{C}$ bond due to increased heat, accelerating the process of decomposition of Lignocellulose. Finally the combustion temperature decreases.

\section{Influence of NZ on LHV}

Table 3 shows the heat released (LHV) by the burning of AF at various NZ. The change of mean heat released caused addition of NZ is presented in Fig. 8. It can be seen that at small sample $(10 \mathrm{mg})$ the addition of NZ increases LHV since the decomposition rate takes place along the process as shown in Fig. 2a. However at larger samples (15 mg and $20 \mathrm{mg}$ ) increasing NZ reduces slightly LHV. This is due to the fact that decomposition of AF is completed much earlier at lower temperature (see Fig. 2b and 2c) so that as the time proceeds the NZ does not work to decompose cellulose but
Table 3 Heat released by AF at various NZ

\begin{tabular}{|c|c|c|c|c|c|c|c|c|c|}
\hline \multirow[t]{3}{*}{ No } & \multicolumn{3}{|c|}{$\mathrm{AF} 1=10 \mathrm{mg}$} & \multicolumn{3}{|c|}{$\mathrm{AF} 2=15 \mathrm{mg}$} & \multicolumn{3}{|c|}{$\mathrm{AF} 3=20 \mathrm{mg}$} \\
\hline & 1 & 2 & 3 & 4 & 5 & 6 & 7 & 8 & 9 \\
\hline & $0 \%$ & $15 \% \mathrm{NZ}$ & $25 \% \mathrm{NZ}$ & $0 \%$ & $15 \% \mathrm{NZ}$ & $25 \% \mathrm{NZ}$ & $0 \%$ & $15 \% \mathrm{NZ}$ & $25 \% \mathrm{NZ}$ \\
\hline Preheat $(\mathrm{J} / \mathrm{g})$ & 56.13 & 21.14 & 33.75 & 72.85 & 51.72 & 69.3 & 54.52 & 57.51 & 34.84 \\
\hline MainHeat (J/g) & 6365.16 & 6873.44 & 7690.46 & 6820.55 & 6845.2 & 5855.69 & 5930.45 & 5454.2 & 5376.67 \\
\hline Onset point ${ }^{0} \mathrm{C}$ & 240.4 & 244.3 & 249.6 & 206.4 & 212.6 & 235.1 & 190.1 & 203.7 & 205.9 \\
\hline Offset point ${ }^{0} \mathrm{C}$ & 560.3 & 599.7 & 611.5 & 795.5 & 744 & 642.3 & 844.4 & 762.6 & 732.9 \\
\hline
\end{tabular}




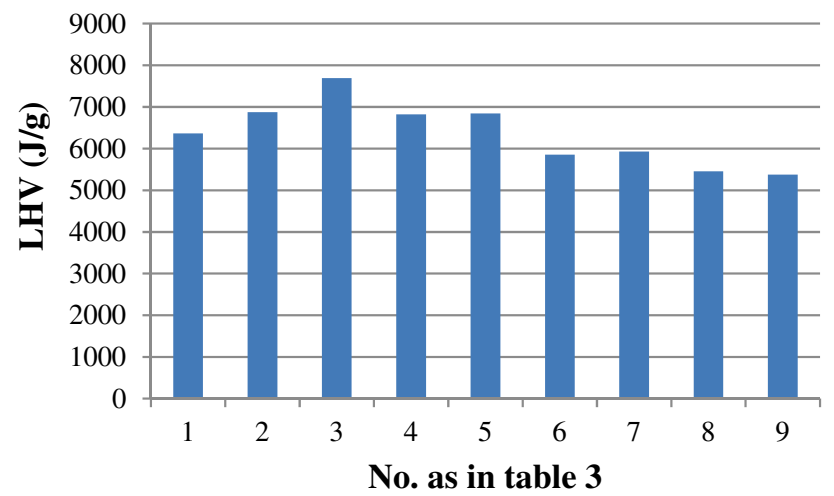

Fig. 8 The change of mean heat released by combustion of AF at various NZ

absorbs heat of combustion slightly. Consequently the LHV decreases slightly.

\subsection{Influence of NZ on ash chemical composition}

As presented in Table 2 the chemical compositions in ash (Wt\%) of AF change over addition of NZ. All minerals which are not component of $\mathrm{NZ}$ reduce. The $\mathrm{Ca}$, which is responsible for agglomeration and corrosion [6] reduces drastically. The Si which is increased largely together with $\mathrm{O}$ due to the NZ addition which is composed mainly by silica and alumina. This result suggests that addition of $\mathrm{NZ}$ makes AF suitable for boiler fuel.

\section{Conclusions}

The study of AF combustion with the addition of NZ has been shown to reduce flame temperature. Proper addition of $\mathrm{NZ}$ can accelerate the devolatization of AF which eventually speeds up the combustion process. The role of alkali metal and alkaline metal earth in NZ can break the lignocellulose polymer chain so that it decomposes quickly into a monomer. The monomer then decomposes into several flammable gases. However, the ratio of AF and NZ affects the combustion process. The addition of NZ to the small number of AF burning makes NZ to become a thermal load. When the weight of $\mathrm{AF}$ is high, the addition of the right percentage of $\mathrm{AF}$ accelerates the process of breaking $\mathrm{C}-\mathrm{O}-\mathrm{C}$ bonds. Addition of $15-20 \%$ of NZ decreases the ignition temperature within faster burning rate. Activated alkali metal and alkaline metal earth decompose hemicellulose faster so that they burn completely in minimizing pollutant and maximizing LHV. At greater number of NZ, the decomposition is completed much earlier so that as the time proceeds NZ does not work to decompose cellulose but slightly absorbs heat sinking LHV. The Ca that is responsible for agglomeration and corrosion decreases to a minimum number due to NZ. This makes the AF added with NZ catalyst become suitable for boiler.

Acknowledgements The author expresses his deepest gratitude to Mr. I. Gusti Ketut Puja from Sanata Dharma University, Yogyakarta and Mr. Ngafwan from the Muhammadiyah Surakarta University for the input of useful discussion in this paper.

Funding The author states that this research was financial support from the Indonesian Ministry of Research and Higher Education regarding PDD Grants with contract numbers (001/II.3AU/LPPM/ Research/2016).

Data availability The data used to support the findings of this study are available from the corresponding author upon request.

\section{Compliance with ethical standards}

Conflict of interest The authors declare that they have no conflicts of interest.

Open Access This article is licensed under a Creative Commons Attribution 4.0 International License, which permits use, sharing, adaptation, distribution and reproduction in any medium or format, as long as you give appropriate credit to the original author(s) and the source, provide a link to the Creative Commons licence, and indicate if changes were made. The images or other third party material in this article are included in the article's Creative Commons licence, unless indicated otherwise in a credit line to the material. If material is not included in the article's Creative Commons licence and your intended use is not permitted by statutory regulation or exceeds the permitted use, you will need to obtain permission directly from the copyright holder. To view a copy of this licence, visit http://creativecommons.org/licenses/by/4.0/.

\section{References}

1. Bakaruddin, I.: A review of Albizia falcataria in West Java, Indonesia, and a study of its use in selected smallholder systems. The University of Melbourne, Parkville (1992)

2. J. A. Duke.: Handbook of energy crops. 1983. Available: https:// hort.purdue.edu/newcrop/duke_energy/Albizia_falcataria.html.

3. Lazaroiu, G., Mihaescu, L., Negreanu, G., Pana, C., Pisa, I., Cernat, A., Ciupageanu, D.A.: Experimental investigations of innovative biomass energy harnessing solutions. Energies (2018). https ://doi.org/10.3390/en11123469

4. Lazaroiu, G., Pop, E., Negreanu, G., Pisa, I., Mihaescu, L., Bondrea, A., Berbece, V.: Biomass combustion with hydrogen injection for energy applications. Energy 127, 351-357 (2017). https:// doi.org/10.1016/j.energy.2017.03.133. (ISSN: 0360-5442, eISSN: 1873-6785)

5. Lazaroiu, G., Mihaescu, L., Pisa, I., Pop, E., Negreanu, G.N., Berbece, V., HYDROGEN-An energy vector in efficient combustion of energy willow. In: 2014, 49th international universities power engineering conference (UPEC), ClujNapoca, ROMANIA, SEP 02-05, 2014, ISBN:978-1-4799-6557-1, Book Group Author(s) IEEE. Publisher IEEE (2014). https://doi.org/10.1109/ UPEC.2014.6934830

6. Pisa, I., Lazaroiu, G., Radulescu, C., Mihaescu, L.: Experimental studies on the corrosion occurrence during biomass combustion 
process. Environ Eng Manag J 11(9), 1555-1560 (2012). https:// doi.org/10.30638/eemj.2012.19

7. Demirbas, A.: Combustion characteristics of different biomass fuels. Prog. Energy Combust. Sci. 30(2), 219-230 (2004)

8. Kantarelis, E., Yang, W., Blasiak, W.: Effect of zeolite to binder ratio on product yields and composition during catalytic steam pyrolysis of biomass over transition metal modified HZSM5. Fuel 122, 119-125 (2014)

9. Horne, P.A., Williams, P.T.: The effect of zeolite ZSM-5 catalyst deactivation during the upgrading of biomass-derived pyrolysis vapours. J. Anal. Appl. Pyrolysis 34(1), 65-85 (1995)

10. Horne, P.A., Williams, P.T.: Upgrading of biomass-derived pyrolytic vapours over zeolite ZSM-5 catalyst: effect of catalyst dilution on product yields. Fuel 75(9), 1043-1050 (1996)

11. Azeez, A.M., Meier, D., Odermatt, J., Willner, T.: Journal of analytical and applied pyrolysis effects of zeolites on volatile products of beech wood using analytical pyrolysis. J. Anal. Appl. Pyrolysis 91(2), 296-302 (2011)

12. Gil, M.V., Casal, D., Pevida, C., Pis, J.J., Rubiera, F.: Bioresource technology thermal behaviour and kinetics of coal/biomass blends during co-combustion. Bioresour. Technol. 101(14), 5601-5608 (2010)

13. Kai, X., Yang, T., Huang, Y., Sun, Y., He, Y., Li, R.: The effect of biomass components on the co-combustion characteristics of biomass with coal. Second Int. Conf. Digit. Manuf. Autom. 2011, 1274-1278 (2011)

14. Shen, B., Qinlei, : Study on MSW catalytic combustion by TGA. Energy Convers. Manag. 47(11-12), 1429-1437 (2006)

15. Zhaosheng, Y., Xiaoqian, M., Ao, L.: Kinetic studies on catalytic combustion of rice and wheat straw under air- and oxygenenriched atmospheres, by using thermogravimetric analysis. Biomass Bioenerg 32(11), 1046-1055 (2008)

16. Zhang, L., Duan, F., Huang, Y.: Bioresource Technology Thermogravimetric investigation on characteristic of biomass combustion under the effect of organic calcium compounds. Bioresour. Technol. 175, 174-181 (2015)

17. Shen, D.K., Gu, S., Luo, K.H., Bridgwater, A.V., Fang, M.X.: Kinetic study on thermal decomposition of woods in oxidative environment. Fuel 88(6), 1024-1030 (2009)

18. Kusuma, R.I., Hadinoto, J.P., Ayucitra, A., Soetaredjo, F.E., Ismadji, S.: Natural zeolite from Pacitan Indonesia, as catalyst support for transesterification of palm oil. Appl. Clay Sci. 74, 121-126 (2013)

19. Hernawan, Wahono, S.K., Maryana, R., Pratiwi, D.: Modification of Gunungkidul natural zeolite as bioethanol dehydrating agents. Energy Procedia 65, 116-120 (2015)

20. Magdziarz, A., Wilk, M.: Thermogravimetric study of biomass, sewage sludge and coal combustion. Energy Convers. Manag. 75(2013), 425-430 (2018)

21. López-González, D., Fernandez-Lopez, M., Valverde, J.L., Sanchez-Silva, L.: Thermogravimetric-mass spectrometric analysis on combustion of lignocellulosic biomass. Bioresour. Technol. 143, 562-574 (2013)

22. Konsomboon, S., Pipatmanomai, S., Madhiyanon, T., Tia, S.: Effect of kaolin addition on ash characteristics of palm empty fruit bunch (EFB) upon combustion. Appl. Energy 88(1), 298-305 (2011)

23. Zhaosheng, Y., Xiaoqian, M., Ao, L.: Thermogravimetric analysis of rice and wheat straw catalytic combustion in air-and oxygenenriched atmospheres. Energy Convers. Manag. 50(3), 561-566 (2009)

24. Gai, C., Zhang, Y., Chen, W.T., Zhang, P., Dong, Y.: Thermogravimetric and kinetic analysis of thermal decomposition characteristics of low-lipid microalgae. Bioresour. Technol. 150, 139-148 (2013)

25. Huber, G.W., Corma, A.: Synergies between bio-and oil refineries for the production of fuels from biomass. Angew. Chemie Int. Ed. 46(38), 7184-7201 (2007)

26. Khan, A.A., De Jong, W., Jansens, P.J., Spliethoff, H.: Biomass combustion in fluidized bed boilers: potential problems and remedies. Fuel Process. Technol. 90(1), 21-50 (2008)

27. Cheng, K., Winter, W.T., Stipanovic, A.J.: A modulated-TGA approach to the kinetics of lignocellulosic biomass pyrolysis/ combustion. Polym. Degrad. Stab. 97(9), 1606-1615 (2012)

28. Yang, H., Yan, R., Chen, H., Zheng, C., Lee, D.H.: Liang DT, In-depth investigation of biomass pyrolysis based on three major components: hemicellulose, cellulose and lignin. Energy Fuels 201(17), 388-393 (2006)

29. Stefanidis, S.D., Kalogiannis, K.G., Iliopoulou, E.F., Michailof, C.M., Pilavachi, P.A., Lappas, A.A.: Journal of analytical and applied pyrolysis a study of lignocellulosic biomass pyrolysis via the pyrolysis of cellulose, hemicellulose and lignin. J. Anal. Appl. Pyrolysis 105, 143-150 (2014)

30. Pang, C.H., Gaddipatti, S., Tucker, G., Lester, E., Pang, C.H., Gaddipatti, S., Tucker, G., Lester, E., Wu, T.: Relationship between thermal behaviour of lignocellulosic components and properties of biomass. Bioresour. Technol. 172, 312-320 (2014)

31. Williams, P.T., Williams, S.B.: The influence of temperature and heating rate on the slow pyrolisis of biomass. Renew. Energy 1481(96), 6-7 (1996)

32. Liu, Y., Che, D., Xu, T.: Catalytic reduction of $\mathrm{SO}_{2}$ during combustion of typical Chinese coals. Fuel Process. Technol. 79(2), 157-169 (2002)

33. Shenqi, X., Zhijie, Z., Jie, X., Guangsuo, Y., Fuchen, W.: Effects of alkaline metal on coal gasification at pyrolysis and gasification phases. Fuel 90(5), 1723-1730 (2011)

Publisher's Note Springer Nature remains neutral with regard to jurisdictional claims in published maps and institutional affiliations. 